Open Access

\title{
Increased expression and functionality of the gap junction in peripheral blood lymphocytes is associated with hypertension-mediated inflammation in spontaneously hypertensive rats
}

\author{
Xin $\mathrm{Ni}^{1,2+}$, Xin-zhi $\mathrm{Li}^{3 \dagger}$, Zhi-ru Fan ${ }^{1,2+}$, Ai Wang ${ }^{1,2}$, Hai-chao Zhang ${ }^{1,2}$, Liang Zhang ${ }^{1,2^{*}}$, Li LI ${ }^{1,2}$, Jun-qiang Si ${ }^{1,2}$ \\ and Ke-tao $\mathrm{Ma}^{1,2^{*}}$ (i)
}

\footnotetext{
* Correspondence:

maketao@hotmail.com; zhangliang_0622@163.com

${ }^{\dagger}$ Xin Ni, Xin-zhi Li and Zhi-ru Fan contributed equally to this work.

'Department of Physiology, Medical College of Shihezi University, 59 North 2nd Road, Shihezi, Xinjiang 832002, People's Republic of China Full list of author information is available at the end of the article
}

\begin{abstract}
Background: Imbalances in circulating T lymphocytes play critical roles in the pathogenesis of hypertension-mediated inflammation. Connexins (CXs) in immune cells are involved in the maintenance of homeostasis of T lymphocytes. However, the association between Cxs in peripheral blood T lymphocytes and hypertensionmediated inflammation remains unknown. This study was designed to investigate the role of Cxs in T lymphocytes in hypertension-mediated inflammation in spontaneously hypertensive rats (SHRs).

Methods: The systolic blood pressure (SBP) in Wistar-Kyoto (WKY) rats and SHRs was monitored using the tail-cuff method. The serum cytokine level was determined using ELISA. The proportions of different T-lymphocyte subtypes in the peripheral blood, the expressions of $\mathrm{C} \times 40 / \mathrm{C} \times 43$ in the T-cell subtypes, and the gap junctional intracellular communication (GJIC) of peripheral blood lymphocytes were measured using flow cytometry (FC). The accumulations of $\mathrm{C} \times 40 / \mathrm{C} \times 43$ at the plasma membrane and/or in the cytoplasm were determined using immunofluorescence staining. The in vitro mRNA levels of cytokines and GJIC in the peripheral blood lymphocytes were respectively examined using real-time PCR and FC after treatment with Gap27 and/or concanavalin A (Con A).

Results: The percentage of $\mathrm{CD} 4^{+} \mathrm{T}$ cells and the $\mathrm{CD} 4^{+} / \mathrm{CD} 8^{+}$ratio were high, and the accumulation or expressions of $\mathrm{C} \times 40 / \mathrm{C} \times 43$ in the peripheral blood lymphocytes in SHRs were higher than in those of WKY rats. The percentage of $\mathrm{CD}^{+}$and $\mathrm{CD}^{+} \mathrm{CD} 25^{+} \mathrm{T}$ cells was lower in SHRs. The serum levels of IL-2, IL-4 and IL-6 from SHRs were higher than those from WKY rats, and the serum levels of IL-2 and IL-6 positively correlated with the expression of $\mathrm{C} \times 40 / \mathrm{C} \times 43$ in the peripheral blood $\mathrm{T}$ lymphocytes from SHRs. The peripheral blood lymphocytes of SHRs exhibited enhanced GJIC. Cx43-based channel inhibition, which was mediated by Gap27, remarkably reduced GJIC in lymphocytes, and suppressed IL-2 and IL-6 mRNA expressions in Con A stimulated peripheral blood lymphocytes.

(Continued on next page)
\end{abstract}


(Continued from previous page)

Conclusions: Our data suggest that Cxs may be involved in the regulation of Tlymphocyte homeostasis and the production of cytokines. A clear association was found between alterations in Cxs expression or in Cx43-based GJIC and hypertensionmediated inflammation.

Keywords: Hypertension-mediated inflammation, T lymphocytes, Connexins, Spontaneously hypertensive rats

\section{Background}

Hypertension has been clearly documented as a major risk factor for myocardial infarction, heart failure, stroke and renal failure. It contributes to more than 7 million deaths annually [1]. Low grade systemic inflammation has been recognized to exert a crucial role in the pathogenesis of hypertension and elevated blood pressure [2]. Studies using various hypertensive experimental models and clinical studies both indicate that the cells of the innate and adaptive immune systems, in particular the various T-lymphocyte subsets, participate in the development of hypertension-mediated inflammation [3-5]. The presence of effector $\mathrm{T}$ lymphocytes is considered a precondition for Ang II or desoxycorticosterone acetate salt hypertension in recombinase-activating gene-knockout mice $[6,7]$. $\mathrm{CD}_{4}^{+}$and $\mathrm{CD}^{+}{ }^{+} \mathrm{T}$ cells are required for Ang II-induced vascular remodeling [8]. Studies using spontaneously hypertensive rats (SHRs) suggest that inflammatory $\mathrm{T}$ cell infiltration may the cause rather than the result of hypertension [7]. Inhibition of the adaptive immune system, lack of effector $\mathrm{T}$ lymphocytes and various immunosuppressive agents can attenuate blood pressure elevation in experimental models and in humans [9-11].These studies demonstrate that hypertensive inflammation-induced T-cell activation and dysregulation of the function of T-lymphocyte subsets are important underlying mechanisms in the pathogenesis of hypertension. An abnormal alteration of effector $\mathrm{T}$ lymphocytes and regulatory $\mathrm{CD}^{+} \mathrm{CD} 25^{+} \mathrm{T}$ lymphocytes (Tregs) is also a important mechanism causing hypertension-mediated inflammation and contributing to blood pressure elevation [4]. Stimulation of Ang II has been found to reduce splenic Tregs and accelerate apoptosis of Tregs in vitro [10]. Tregs counteract hypertension-mediated inflammation by blocking innate and adaptive immune responses [12-14]. Studies have shown that T lymphocyte-derived pro-inflammatory cytokines, such as IL-1 $\beta$, IL-2, IL-6, TNF- $\alpha$ and IFN- $\gamma$, are produced in excess with significantly upregulated expressions in different hypertensive models $[9,15]$. High levels of circulating pro-inflammatory cytokines have been found in hypertensive patients, and the plasma levels of pro-inflammatory cytokines can be used to predict the onset of hypertension [16, 17]. This implies that these pro-inflammatory cytokines, which are produced by effector $\mathrm{T}$ lymphocytes, can contribute to further progression of hypertension-mediated inflammation. While all this compelling evidence suggests that an imbalance in $\mathrm{T}$ lymphocytes and proinflammatory cytokines can lead to hypertension, the exact mechanisms causing this imbalance in the adaptive immune system during the development and maintenance of hypertension remain to be elucidated.

The homeostasis of the immune system and efficient immune responses against chronic pathologies (e.g., hypertension and diabetes) require efficient coordination between different immune cell types. This homeostasis are modulated by the actions of 
three communication mechanisms at the intracellular, extracellular and intercellular levels [18]. The direct intercellular signaling mechanism for cell-cell interaction is mainly mediated by gap junction channels (GJCs) $[18,19]$. GJCs are specialized regions on the plasma membrane that are formed by the docking of two opposing hemi-channels (HCs) between adjacent cells [18]. GJCs and HCs consist of Cxs protein families, which are present in almost all immune cells [20, 21]. Cxs-based hemi-channels (Cx-HCs) are composed of six identical Cxs (a homomeric connexon) or a mixture of Cxs types (a heteromeric connexon) [22]. In general, when the immune cells become activated or exposed to inflammatory factors, they can use Cxs-based GJCs to control immune responses by transferring immunorelevant signals between neighboring cells in the form of ions, second messengers, small metabolites and peptides [20]. Cx43 is the most important pro-inflammatory Cx protein of the five main Cx proteins (Cx30.3, Cx32, Cx37, Cx40 and Cx43) found in multiple cell types of the immune and lymphatic systems $[18,23]$. Some experimental evidence indicates that $\mathrm{Cx} 43$ can control the activation, proliferation and terminal differentiation of $\mathrm{T}$ lymphocytes, immunoglobulin secretion, and cytokine production by establishing GJCs between $\mathrm{T}$ lymphocytes and dendritic cells or macrophages [24, 25].

It is clear that Cxs-based GJCs in immune cells play a pivotal role in specific immune responses. Although results from the above-mentioned in vitro and in vivo studies have suggested that Cxs-based channels in immune system can modulate immune processes, their role in the regulation of hypertension-mediated inflammation remains unclear. To further explore the link between the expression or function of Cxs, alterations in T-lymphocyte subsets, and pro-inflammatory cytokine production during hypertension, we used SHRs. We measured alteration in the various T-lymphocyte subtypes, determined the expressions of $\mathrm{Cxs}(\mathrm{Cx} 40$ and $\mathrm{Cx} 43)$ in peripheral blood lymphocytes, evaluated the function of Cx43-based channel-mediated gap junctional intracellular communication (GIIC), and quantified the serum inflammatory cytokine level. A blocker of Cx43-based channels was used to further investigate the association between the function of $\mathrm{Cx} 43$ based-channels and hypertension-mediated inflammation. We found that alteration in peripheral blood T-cell subsets in SHRs is associated with a significant increase in Cxs expression and the activities of Cx43-based channels. We identified a possible role for $\mathrm{Cx} 43$ in the control of pro-inflammatory cytokine synthesis during hypertension.

\section{Methods}

\section{Experimental animals}

Age-matched 16-week old male spontaneously hypertensive rats (SHRs) and normotensive Wistar-Kyoto (WKY) rats (Vital River Laboratory Animal Technology Co., Ltd.) were used in this study. All rats were housed in temperature- and humidity-controlled quarters with a 12-h light cycle, and had free access to standard rat chow and water. All live animal experiments performed in this study complied with the guidelines from the Institutional Animal Care and Use Committee (IACUC) of the Medical College of Shihezi University.

\section{Blood pressure monitoring}

The rats were acclimatized for 7 days, and the systolic blood pressure was measured non-invasively with a tail cuff apparatus with a pneumatic pulse transducer 
(Chengdu Taimeng Software Co. Ltd.) prior to the experiment, as described in our previous report [26]. For the measurement, the rats were held in a warming chamber at $37{ }^{\circ} \mathrm{C}$ and the tail cuff was placed around the tail of the rats. The averaged blood pressure of each rat was determined from at least three consecutive readings.

\section{Flow cytometric analysis}

Peripheral blood mononuclear cells (PBMCs) from whole blood $(5 \mathrm{ml})$ of WKY rats and SHRs were isolated using a dedicated kit (cat. no. P8630; Solarbio Science \& Technology). $1 \mathrm{ml}$ FACS lysing solution (cat. no. 349202; BD Bioscience) was added and the mixture was incubated for $10 \mathrm{~min}$ at room temperature to remove any remaining RBCs. After a phosphate-buffered saline (PBS) rinse and centrifugation at $1000 \times g$ for $10 \mathrm{~min}$, the number of cells was counted in a hemocytometer chamber and the viability of PBMCs was assessed using Trypan Blue staining. The cell survival rate was determined to be $>95 \%$. Surface staining of T-lymphocyte subtypes (at least $1 \times 10^{6}$ cells $/ \mathrm{ml}$ in $250 \mu \mathrm{l}$ PBS; all anti-rat CD3, CD4, CD8 and CD25 monoclonal antibodies from Biolegend, Inc.) was performed as described previously [26]. Flow cytometry was used to obtain a count for each T-cell subgroup. Flow cytometry was carried out on a FACSort flow cytometer (Mindray Bio-Medical Electronics Co., Ltd.). Populations are expressed as the percentage of the total lymphocyte population.

Determination of Cxs expression in T-lymphocyte subtypes was performed via flow cytometry as described previously [26]. Briefly, PBMCs were permeabilized with a Cytofix/ Cytoperm Kit (BD Biosciences) and labeled with anti-Cx40 monoclonal antibody (cat. no. sc-365,107, Santa Cruz Biotechnology) or anti-Cx43 antibody (cat. no. ab79010, Abcam), followed by FITC-labeled secondary antibody (cat. no. 405305, Biolegend, Inc.). Finally, cells were incubated with anti-CD4 and anti-CD8 antibodies. Two-color immunofluorescence flow cytometry was used to analyze $\mathrm{Cx} 40 / \mathrm{Cx} 43$ expression in $\mathrm{CD}^{+}$and $\mathrm{CD} 8^{+} \mathrm{T}$ lymphocytes.

\section{Serum cytokine detection via ELISA}

The SHRs and WKY rats were euthanized using $30 \mathrm{mg} / \mathrm{l}$ sodium pentobarbital anesthesia (50 $\mathrm{mg} \mathrm{kg}^{-1}$, i.p.). Peripheral blood was collected into heparin-coated plain tubes. The serum was obtained by centrifugation of blood at $800 \times g$ for 15 min at $4{ }^{\circ} \mathrm{C}$. Enzyme-linked immunosorbent assay (ELISA) was used to measure the concentrations of cytokines (IL-2, IFN- $\gamma$, IL-4 and IL-6) in the serum according to the manufacturer's instructions (cat. no. 70-EK3022/2 for IL-2; cat. no. 70-EK3042/2 for IL-4; cat. no. 70-EK3062/2 for IL-6; cat. no. 70-EK3802/2 for IFN- $\gamma$; MultiSciences Biotech Co., Ltd.). The reaction was measured at $450 \mathrm{~nm}$ with a microplate reader (Dynatech). The level of each cytokine in serum was calculated according to the standard curve of each murine recombinant cytokine and expressed in $\mathrm{pg} / \mathrm{ml}$.

\section{Cell culture and drug treatment}

PBMCs were isolated from WKY rats and SHRs using an isolation kit for mononuclear cells (cat. no. P8630; Solarbio Science \& Technology) and then incubated for $3 \mathrm{~h}$ in 1 
ml RPMI-1640 media (cat. no. 11875085; Gibco Brand; Invitrogen by Life Technologies) containing 10\% fetal bovine serum (FBS; cat. no. SH30084; HyClone), $100 \mathrm{U}$ penicillin and $100 \mu \mathrm{g} / \mathrm{ml}$ streptomycin (cat. no. P0781; Sigma Aldrich) at $37{ }^{\circ} \mathrm{C}$ in an incubator with $5 \% \mathrm{CO}_{2}$. After $3 \mathrm{~h}$ incubation, non-adherent $\mathrm{T}$ lymphocytes were collected following gentle pipetting the medium, and adjusted to $1 \times 10^{6}$ cells $/ \mathrm{ml}$ in medium. Cultured T lymphocytes were incubated for the indicated times with $5 \mu \mathrm{g} / \mathrm{ml}$ concanavalin A (Con A; cat. no. C5275; Sigma Aldrich) and/or $500 \mu \mathrm{M}$ Gap27, which is a peptide (SRPTEKTIFII) derived from extracellular loop II of connexin 43 (cat. no. A1045; ApexBio Technology LCC) according to the experimental requirements. All cells were cultured in RPMI-1640 with 10\% FBS. A control group of lymphocytes was cultured under the same conditions without Con A or Gap27. All treatments were carried out in triplicate. The cultures were incubated at $37{ }^{\circ} \mathrm{C}$ in a $5 \% \mathrm{CO}_{2}$ atmosphere in a humidified incubator.

\section{Immune fluorescence staining}

Cultured peripheral blood lymphocytes $\left(1 \times 10^{5}\right.$ cells $\left./ \mathrm{ml}\right)$ from WKY rats and SHRs without any drug treatment were washed with PBS and fixed with $4 \%$ paraformaldehyde for $30 \mathrm{~min}$ at room temperature. After washing in PBS, lymphocytes were permeabilized with $0.5 \%$ Triton-X 100 plus $0.5 \%$ FBS for $10 \mathrm{~min}$ at room temperature, and then blocked with PBS containing 1\% BSA. After blocking, permeabilized lymphocytes were incubated with anti-Cx40 polyclonal and anti-Cx43 monoclonal antibodies (cat. no. ab183648 for Cx40; cat. no. ab79010 for $\mathrm{Cx} 43$, Abcam) overnight at $4{ }^{\circ} \mathrm{C}$. $\mathrm{Cx} 40$ and $\mathrm{Cx} 43$ expressions were detected using fluorescently labeled secondary goat anti-rabbit rhodamine-conjugated antibodies (cat. no. ZF0316, Zsbio) and goat anti-mouse FITC-conjugated antibody (cat. no. ZF0312, Zsbio). Additionally, cell nuclei were labelled with $1 \mu \mathrm{g} / \mathrm{ml}$ Hoechst 33342 (cat. no. 62249, Thermo Fisher Scientific) in PBS for $30 \mathrm{~min}$ at room temperature. Finally, the lymphocytes were visualized analyzed using a Zeiss LSM510 confocal microscope (Carl Zeiss) with a $63 \times$ oil immersion objective (numerical aperture: 1.40). Adobe Photoshop software was used to adjust the contrast, and compose and overlay the images. The mean fluorescence intensities of Cx40 and Cx43 labelling in the cytoplasm and at the plasma membrane were quantified using Image J software (National Institutes of Health). 50 peripheral blood lymphocytes from different rats $(n=5)$ were analyzed on $\sim 25$ fields in at least three experiments. Two independent investigators evaluated the data. The fluorescence intensities were displayed on a pseudocolor scale (16 colors) using the Image J software.

\section{Gap junctional intracellular communication (GJIC) assay}

Flow cytometry with calcein acetoxymethyl ester (calcein AM) [22, 27] was used to compare the functionality of GIC between peripheral blood lymphocytes from WKY rats and SHRs. Briefly, isolated peripheral blood lymphocytes $\left(1 \times 10^{6}\right.$ cells $\left./ \mathrm{ml}\right)$ were loaded with $10 \mathrm{mM} \mathrm{DiIC} 18$ (cat. no. D282; Invitrogen) or $2.5 \mathrm{mM}$ calcein AM (cat. no. 3099; Invitrogen) for $30 \mathrm{~min}$ at $37{ }^{\circ} \mathrm{C}$ in RPMI-1640 containing $10 \% \mathrm{FBS}$. The $\mathrm{DiIC}_{18}$ or calcein single-stained peripheral blood lymphocytes were washed in PBS containing $1 \%$ BSA and then mixed at a ratio of 1:100 (calcein-loaded:DiI$\mathrm{C}_{18}$-loaded). After seeding for $30 \mathrm{~min}$, co-cultured peripheral blood lymphocytes 
were incubated in the absence or presence of Con A $(5 \mu \mathrm{g} / \mathrm{ml})$ and/or Gap27 $(500 \mu \mathrm{M})$. After co-culture for $3 \mathrm{~h}$, co-cultured lymphocytes in each group were collected, washed with PBS containing $10 \mathrm{mM}$ EDTA and resuspended in PBS containing 1\% BSA. Calcein AM (excitation at $488 \mathrm{~nm}$ and emission at $535 \mathrm{~nm}$ ) and $\mathrm{DiIC}_{18}$ (excitation at $488 \mathrm{~nm}$ and emission at $585 \mathrm{~nm}$ ) fluorescence were assessed using flow cytometry as described previously [27].

\section{Quantitative real-time PCR analysis of IL-2 and IL-6 mRNA expression}

Cultured T lymphocytes from WKY rats and SHRs were divided into the following groups: Con A $(5 \mu \mathrm{g} / \mathrm{ml})$ treatment group (cells treated with Con A for $24 \mathrm{~h})$; Con A plus Gap27 $(500 \mu \mathrm{M})$ treatment group (cells pretreated for $48 \mathrm{~h}$ with Gap27, and then stimulated with Con A for $24 \mathrm{~h}$ ); and the control group without incubation of Con A or Gap27. Total RNA was extracted from cultured T lymphocytes from WKY rats and SHRs using TRI Reagent. RNA concentration and purity were determined using a NanoVue spectrophotometer (GE Healthcare Biosciences). $100 \mathrm{ng}$ total RNA was used to synthesize cDNA via reverse transcription with PrimeScript 1st Strand cDNA Synthesis Kit (cat. no. 6110B; Takara Biotechnology Co., Ltd.) in accordance with the manufacturer's instructions. The gene-specific primers of $I L-2, I L-6$ and GAPDH were designed by Oligo 7.0. The primer sequences were:

\section{IL-2 forward primer: 5'-GCA CCT GTA AGT CCA GCA AC-3' \\ IL-2 reverse primer: 3'-ACG CTT GTC CTC CTT GTC A-5' \\ IL-6 forward primer: 5'-TTG GGA CTG ATG TTG TTG-3' \\ IL-6 reverse primer: $3^{\prime}$-TGT GGG TGG TAT CCT CTG T-5' \\ GAPDH forward primer: 5'-CTC TCT GCT CCT CCC TGT TC-3' \\ GAPDH reverse primer: 3'-GCC AAA TCC GTT CAC ACC G-5'}

Quantitative real-time PCR was performed with SYBR Premix Ex Taq II (cat. no. RR820Q; Takara Biotechnology Co., Ltd.) on a CFX96 Touch Deep Well real-time PCR detection system (Bio-Rad). The reaction mix consisted of $12.5 \mu \mathrm{l}$ of $2 \times$ SYBR Premix Ex Taq II, $0.4 \mu \mathrm{M}$ of each primer, and $2 \mu \mathrm{l}$ of cDNA. The PCR cycle was: $95{ }^{\circ} \mathrm{C}$ for $30 \mathrm{~s}$, followed by 40 cycles of $95{ }^{\circ} \mathrm{C}$ for $5 \mathrm{~s}$ and $60{ }^{\circ} \mathrm{C}$ for $30 \mathrm{~s}$. The fluorescent signals were measured at the annealing/extension step. Quantitative real-time PCR was run in triplicate for each group, and the gene expression of triplicates was averaged, referenced to GAPDH, and reported relative to the average relative expression level in the control samples (peripheral blood lymphocytes from WKY rats). The relative expression of the each gene was calculated using the $2^{-\triangle \triangle \mathrm{Ct}}$ method (Schmittgen and Livak, 2008) with GAPDH as a housekeeping control gene.

\section{Statistical analysis}

All experimental data are shown as the means \pm SEM and assessed using Student's $t$-test for the comparison of two groups or using one-way analysis of variance (ANOVA). The Pearson product-moment correlation coefficient ( $r$ ) was used to assess the relationship between $\mathrm{Cx} 40$ and $\mathrm{Cx} 43$ expression levels and the serum level of pro-inflammatory cytokines. Statistical analysis was performed using GraphPad Prism 
version 5.0 (GraphPad Software), and $p<0.05$ or $p<0.01$ was considered to statistically significant (details described in the legend of each figure).

\section{Results}

Systematic analysis of body weight, spleen weight and systolic blood pressure between SHRs and WKY rats

The basal systolic blood pressure (SBP) of WKY rats and SHRs was measured before the experiments. At 16-17 weeks of age, the SBP was significantly higher in SHRs (205.5 \pm $10.5 \mathrm{mmHg})$ than in age-matched WKY rats $(119.6 \pm 10.1 \mathrm{mmHg} ; p<0.01)$. A tendency toward increased spleen weight (SW) was observed in SHRs, but the difference was not significant compared with the WKY rats. No significant difference was observed in the body weights (BW) or the ratios of SW to BW between SHRs and WKY rats ( $p>0.05$; Table 1).

\section{Hypertension results in the changes in the T-lymphocyte subtypes in the peripheral blood in SHRs}

Several experimental studies in hypertensive models have suggested that disequilibrium in proportion of T-cell subsets contributes to a pro-inflammatory response accompanied by blood pressure elevation [8, 28]. To investigate whether there is an imbalance in T-cell subsets in the SHRs and which subtype of T cells contributes to the inflammatory pathogenesis of hypertension, the proportions of $\mathrm{CD} 4^{+}, \mathrm{CD} 8^{+}$and $\mathrm{CD} 4^{+} \mathrm{CD} 25^{+} \mathrm{T}$ cells from the peripheral blood of SHRs were determined using flow cytometry. Figure 1a shows the percentage of T-cell subsets in blood samples from male SHRs and WKY rats. A significantly higher percentage of $\mathrm{CD}^{+} \mathrm{CD} 4^{+} \mathrm{T}$ cells [WKY vs. SHRs: $(65.08 \pm 0.9) \%$ vs. $(72.84 .1 \pm 0.32) \% ; p<0.01$ ] and a higher ratio of $\mathrm{CD}^{+}$to $\mathrm{CD} 8^{+}$[WKY vs. SHRs: $1.92 \pm 0.05$ vs. $2.7 \pm 0.05 ; p<0.01$ ] were noted in SHRs than in WKY rats (Fig. 1b). However, the frequencies of $\mathrm{CD}^{+} \mathrm{CD}^{+}$[WKY vs. SHRs: $(34.5 \pm 0.56) \%$ vs. $(26.6 \pm 0.39) \% ; p<0.01$ ] and $\mathrm{CD} 4^{+} \mathrm{CD} 25^{+} \mathrm{T}$ cells [WKY vs. SHRs: $(5.63 \pm 0.5) \%$ vs. $(3.78 \pm 0.35) \%$; $p<0.01]$ were significantly lower in the peripheral blood of SHRs compared with WKY rats (Fig. 1b).

Hypertension enhances the production of pro-inflammatory cytokines in the serum of SHRs We then evaluated the secretion of the pro-inflammatory cytokines IL-2, IFN- $\gamma$, IL-4 and IL-6, which are generally regarded as the signs of lymphocyte activation [3]. A significant increase in the serum level of IL-2 [(133.90 \pm 25.40$) \mathrm{pg} / \mathrm{ml}], \mathrm{IL}-4[(1.07 \pm 0.2) \mathrm{pg} / \mathrm{ml}]$ and IL-6 [(28.2 \pm 1.9$) \mathrm{pg} / \mathrm{ml}]$ was observed in SHRs compared with WKY rats $(p<0.05$, Fig. 2$)$. However, no significant differences in IFN- $\gamma$ production were observed between WKY rats $[(7.2 \pm 0.8) \mathrm{pg} / \mathrm{ml}]$ and SHRs $[(8.3 \pm 1.4) \mathrm{pg} / \mathrm{ml}]$ (Fig. 2). The results suggested that hypertension promoted the secretion of pro-inflammatory cytokines.

Table 1 Body weight, blood pressure, spleen weight in the rats

\begin{tabular}{lllll}
\hline Rats & Body weight $(\mathrm{g})$ & SBP $(\mathrm{mm} \mathrm{Hg})$ & Spleen weight $(\mathrm{mg})$ & $\begin{array}{l}\text { Weight ratio of spleen } \\
\text { to body }(\mathrm{mg} / \mathrm{g})\end{array}$ \\
\hline WKY $(n=20)$ & $282.0 \pm 3.2$ & $119.6 \pm 10.1$ & $629.0 \pm 15.6$ & $2.23 \pm 0.1$ \\
SHRs $(n=20)$ & $290.8 \pm 2.9$ & $205.5 \pm 10.5^{* *}$ & $652.5 \pm 11.2$ & $2.17 \pm 0.0$ \\
\hline
\end{tabular}

$S B P$ was increased in $S H R s$ compared with $W K Y$ rats. ${ }^{*} P<0.01$, compared with $W K Y$ group; Data are means $\pm S E M$. SHRs, spontaneously hypertensive rats; WKY, Wistar Kyoto rats 


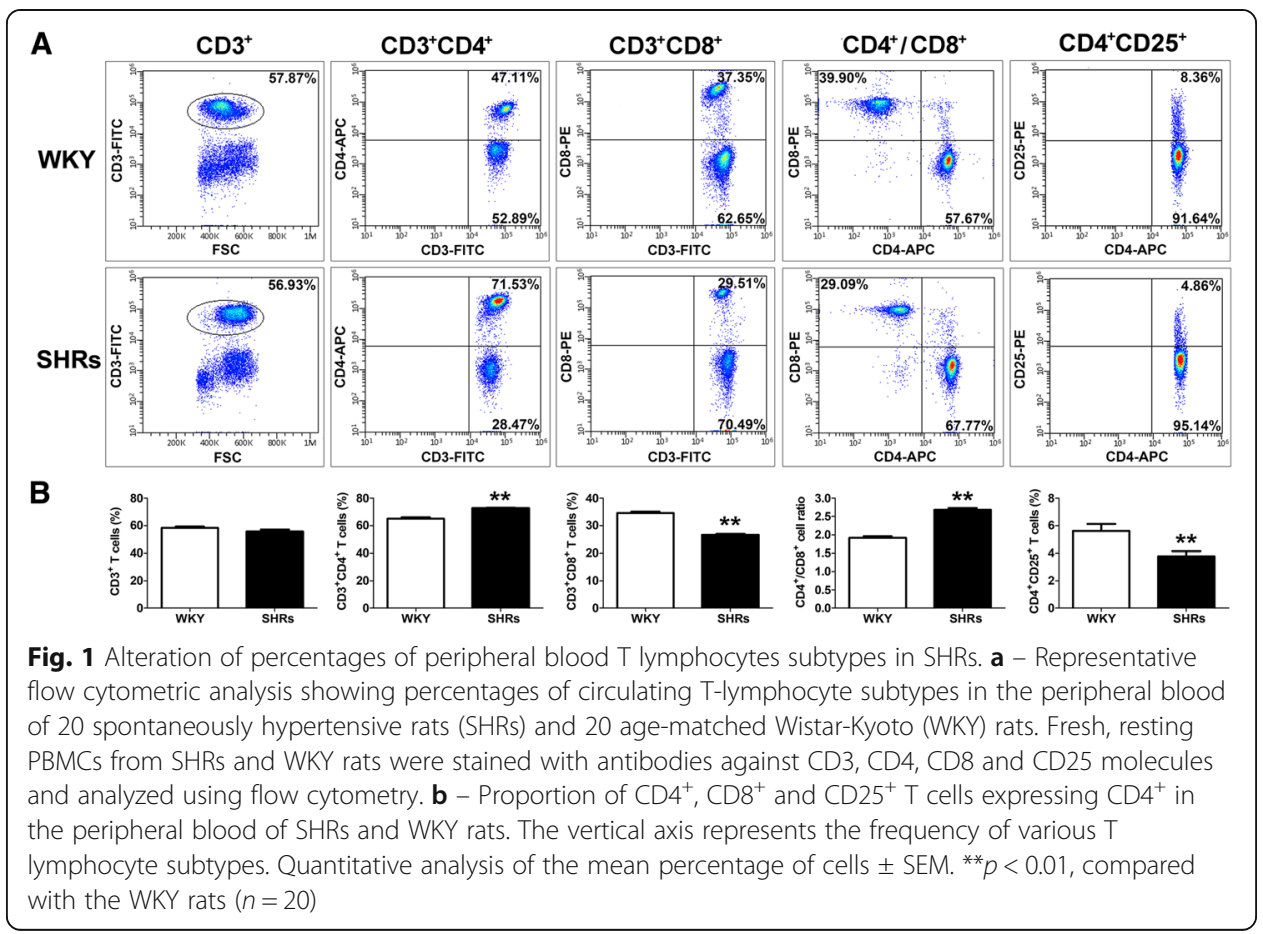

Increased expression of Cxs in the peripheral blood T cells of SHRs correlates with hypertension-mediated inflammation

Various inflammatory stimuli have been reported to upregulate Cxs expression in various lymphocytes $[25,29,30]$. We aimed to examine the cellular distribution of Cx40 and Cx43 in peripheral blood lymphocytes to see whether hypertension-mediated inflammation induces upregulation of $\mathrm{Cx} 40$ and $\mathrm{Cx} 43$ expressions in the peripheral blood lymphocytes of SHRs. Indirect immunofluorescence staining and confocal microscopy were used to study the presence and distribution of $\mathrm{Cx} 40$ and $\mathrm{Cx} 43$ in the cytoplasm and at the plasma membrane of peripheral blood lymphocytes from WKY rats and SHRs. Using permeabilized peripheral blood lymphocytes, the expressions of connexins on the cell surface or in the cytoplasm were studied using anti-Cx40 and -Cx43 antibodies. In line with previous reports $[25,30,31]$, positive $\mathrm{Cx} 40$ and $\mathrm{Cx} 43$ expressions were observed in peripheral blood lymphocytes (Fig. 3a and b), with more intense staining on the surfaces of peripheral blood lymphocytes (Fig. 3a and b). Diffuse Cx40 and Cx43 expressions in the cytoplasm were also seen in permeabilized cells (Fig. 3a and b). Immune fluorescence staining together with analysis of fluorescence intensity indicated that $\mathrm{Cx} 40$ and $\mathrm{Cx} 43$ were also more extensively distributed in both the plasma membranes and cytoplasm of peripheral blood lymphocytes of SHRs than those of WKY rats (Fig. 3a and b; $p<0.01$ or $p<0.05$, details described in the legends of the respective figures).

To further verify these observations, we also performed flow cytometric analysis on different $\mathrm{T}$-cell subtypes $\left(\mathrm{CD}^{+}\right.$and $\mathrm{CD}^{+} \mathrm{T}$ cells) from WKY rats and SHRs. The results showed a significant difference in the expression levels of Cxs in various T-lymphocyte subtypes between WKY rats and SHRs (Fig. 4a and b). The expression levels of Cx40 [CD4 ${ }^{+} \mathrm{Cx} 40$, WKY vs. SHRs: $(3.33 \pm 0.36) \%$ vs. $(8.58 \pm 0.99) \% ; p<0.01$; 


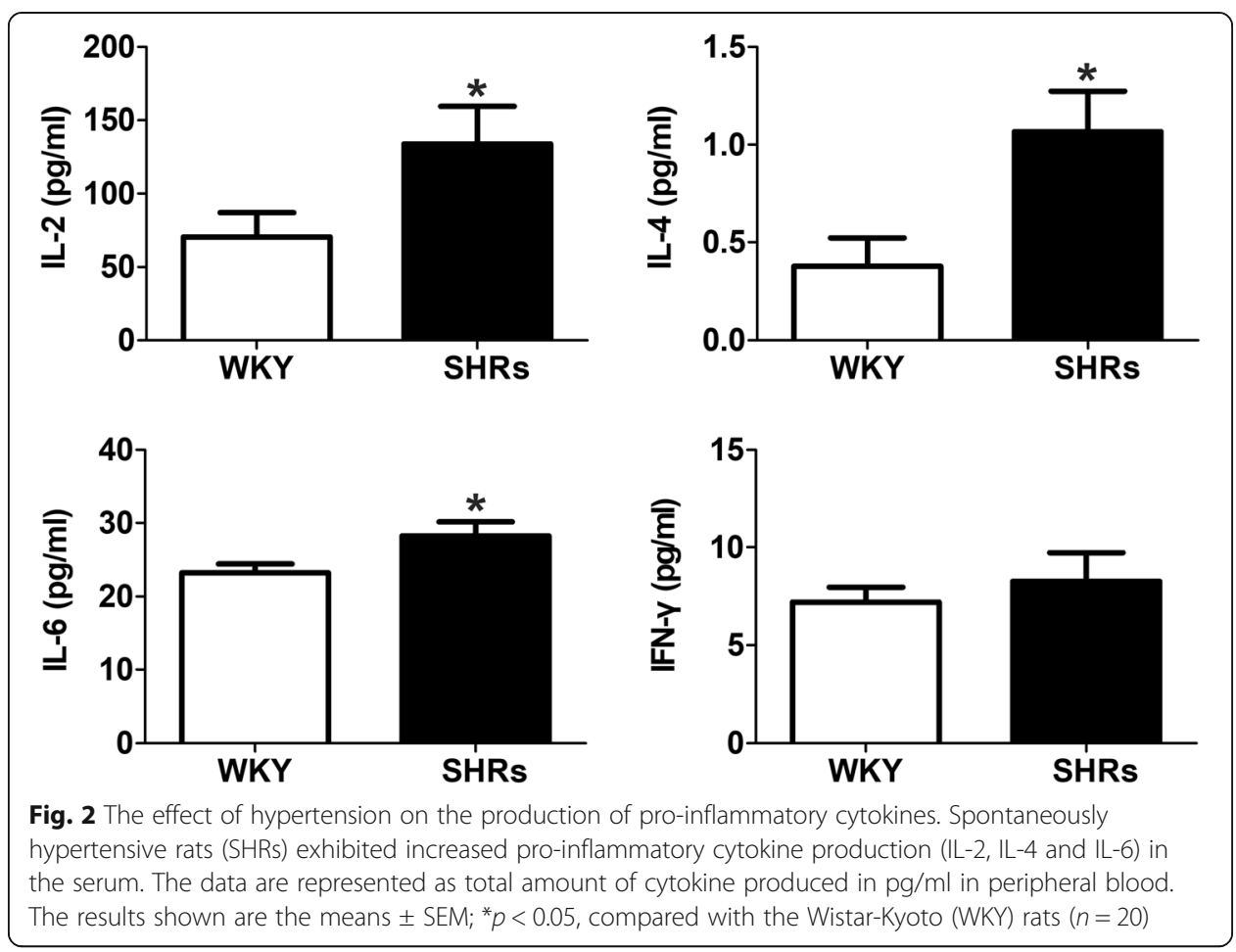

CD8 ${ }^{+} \mathrm{Cx} 40$, WKY vs. SHRs: $(7.64 \pm 0.70) \%$ vs. $\left.(17.14 \pm 1.00) \% ; p<0.01\right]$ and $\mathrm{Cx} 43$ $\left[C D 4{ }^{+} \mathrm{Cx} 43, \mathrm{WKY}\right.$ vs. SHRs: $(1.36 \pm 0.14) \%$ vs. $(6.33 \pm 0.39) \% ; p<0.01 ; \mathrm{CD}^{+} \mathrm{Cx} 43$, WKY vs. SHRs: $(25.18 \pm 1.16) \%$ vs. $(41.84 \pm 2.82) \% ; \mathrm{p}<0.01]$ were higher in $C D 4^{+}$and $\mathrm{CD}^{+} \mathrm{T}$ cells of SHRs $(\mathrm{p}<0.01$, Fig. $4 \mathrm{~b}$ ) compared with those of WKY rats. Interestingly, the expressions of $\mathrm{Cx} 40$ and $\mathrm{Cx} 43$ were higher in $\mathrm{CD}^{+} \mathrm{T}$ cells than those in CD4 ${ }^{+}$T cells.

We extended these results by performing correlation analyses between $\mathrm{Cx} 40$ and Cx43 expressions in peripheral blood $\mathrm{T}$ lymphocytes and the pro-inflammatory cytokines levels in the serum. Linear regression analysis showed that plasma levels of IL-2 positively correlated with the Cxs expressions of T lymphocytes in SHRs $(r=0.81$ for Cx40, $r=0.70$ for Cx43, $p<0.05)$. Similarly, IL-6 levels in the serum positively correlated with the Cx43 expressions of T lymphocytes in SHRs $(r=0.61, p<0.05)$. The results revealed an association between the expressions of $\mathrm{Cx} 40$ and $\mathrm{Cx} 43$ in peripheral blood lymphocytes and elevated serum levels of IL-2 or IL-6 (Table 2).

\section{Enhanced gap junctional intracellular communication in SHR can be blocked by Gap27}

GJIC between different lymphocytes has been previously described [22, 30, 31]. To further determine whether hypertension induces changes in Cx43-mediated GJIC, we used calcein AM-mediated dye transfer assay to compare GJIC between peripheral blood lymphocytes from WKY rats and SHRs. Peripheral blood lymphocytes were stained with $\mathrm{DiIC}_{18}$ and calcein $\mathrm{AM}$, respectively. After $3 \mathrm{~h}$ in co-culture in the absence or presence of Con A or Gap27, there was a significant increase in calcein AM dye transfer between co-cultured cells in SHR control compared with the transfer from the WKY control $(p<0.01$, Fig. 5a and b). This result is consistent with the increased 


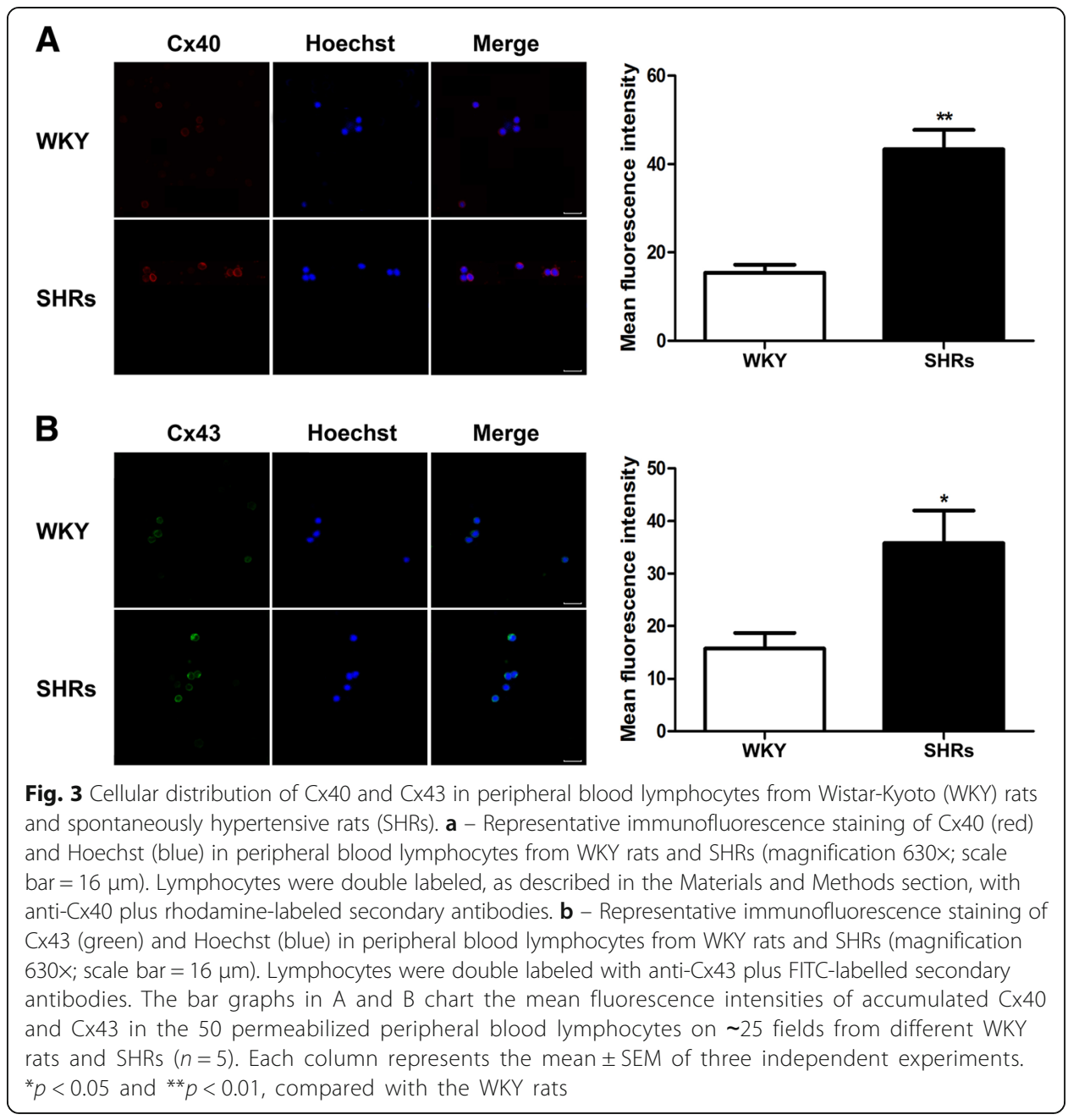

expression levels of Cx43 in peripheral blood lymphocytes of SHRs. Compared with unstimulated cells, the dye transfer in peripheral blood lymphocytes from WKY rats and SHRs was significantly enhanced when the co-cultured cells were incubated with Con A for $3 \mathrm{~h}(p<0.05$ in SHR and $p<0.05$ in WKY, Fig. 5a and b). The specific gap junction inhibitory peptide Gap27 showed an obvious inhibition of dye transfer from calcein AM-stained cells to recipient cells stained with $\mathrm{DiIC}_{18}$ in WKY rats and SHRs $(p<0.05$ in WKY and $p<0.05$ in SHR, Fig. 5). These results are similar to our data for essential hypertensive patients [27], demonstrating a role for $\mathrm{Cx} 43$ in mediating functional GIIC between peripheral blood lymphocytes during hypertension.

Inhibition of the gap junction decreases the expression of pro-inflammatory cytokines

Blocking Cxs-based GJCs in lymphocytes results in the suppression of the synthesis of pro-inflammatory cytokines such as IFN- $\gamma$ and IL-2 [22, 32]. To further investigate the involvement of Cx43-mediated gap junctional intercellular communication in the synthesis of pro-inflammatory cytokines by changed T-cells subsets during hypertension, cultured peripheral blood lymphocytes from SHRs and WKY rats were treated with Con A for $24 \mathrm{~h}$ or pretreated with the Cx43 mimetic peptide Gap27 for $48 \mathrm{~h}$ and then 


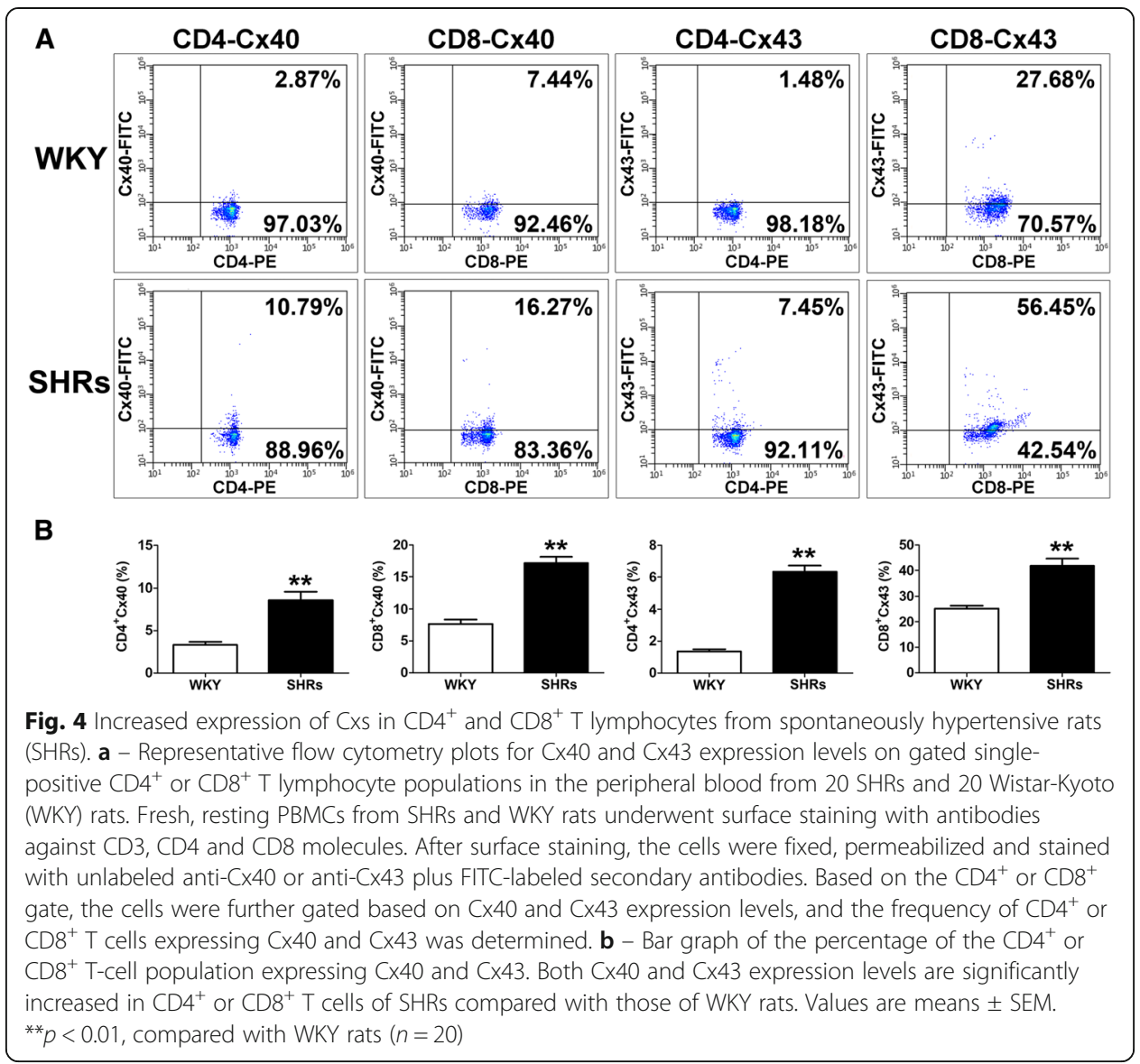

with Con A for 24 h. As shown in Fig. 6, stimulation with Con A increased the expression levels of $I L-2$ and $I L-6$ mRNA in lymphocytes, in particular in SHRs. The increases in SHRs were suppressed severely by pretreatment with Gap27 $(p<0.01$, Fig. 6). Thus, these data indicated that the synthesis of pro-inflammatory cytokines might be regulated directly by Cxs-based channels during hypertension.

\section{Discussion}

For over 50 years, it has been recognized that low-grade systemic inflammation contributes to hypertension. This can be seen in the infiltration of $\mathrm{T}$ lymphocytes and the elevation in the secretion of $\mathrm{T}$ cell-derived pro-inflammatory cytokines in the serum and target organs in different experimental hypertension models [33]. Alterations in the expression and function of Cxs are a well-documented event of the inflammatory response and are known to contribute to changes in the proliferation and activation of $\mathrm{T}$ lymphocytes and in inflammatory cytokine production [24, 25]. However, these

Table 2 The correlation analysis between serum levels of pro-inflammatory cytokines and Cxs expression of $\mathrm{T}$ lymphocytes in SHRs

\begin{tabular}{lllll}
\hline & $\mathrm{IL}-2$ & $\mathrm{IFN}-\gamma$ & $\mathrm{IL}-4$ & $\mathrm{IL}-6$ \\
\hline $\mathrm{C} \times 40$ & $r=0.81$ & $r=0.66$ & $r=0.33$ & $r=0.32$ \\
& $P<0.05^{*}$ & $P>0.05$ & $P>0.05$ & $P>0.05$ \\
$\mathrm{C} \times 43$ & $r=0.45$ & $r=0.60$ & $r=0.61$ \\
& $r=0.70$ & $P>0.05$ & $P>0.05$ & $P<0.05^{*}$ \\
\hline
\end{tabular}


Ni et al. Cellular \& Molecular Biology Letters (2018) 23:40

Page 12 of 18

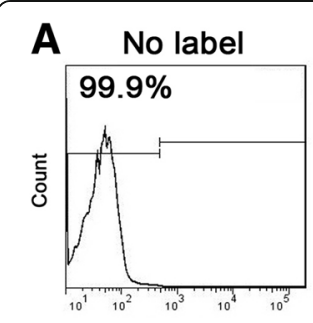

WhY

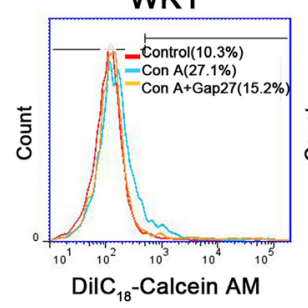

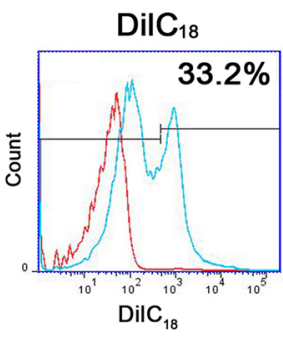

SHR

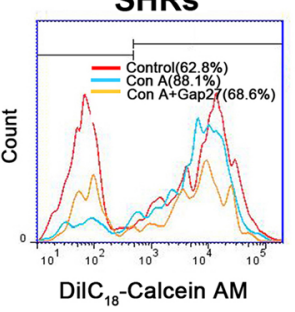

Calcein AM

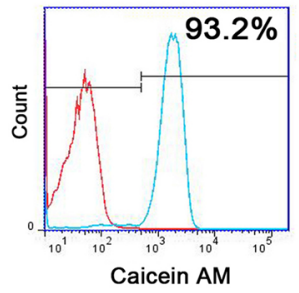

B

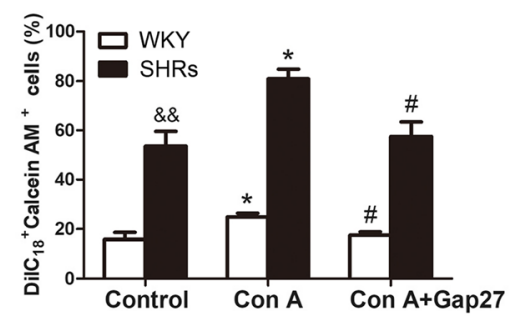

Fig. 5 Effect of hypertension-mediated inflammation and blocking of the gap junction on gap junctional intracellular communication ( GIC) between peripheral blood lymphocytes from spontaneously hypertensive rats (SARs). The X-axis represents the parameter's signal value in the channel numbers (count) and the Y-axis represents the number of events per channel number (calcein AM- and/or Dill ${ }_{18}$-positive cells). $\mathbf{a}$ Control experiments of Dill $_{18}$ or calcein AM single-stained lymphocytes and $\mathrm{DilC}_{18}$-calcein double-stained lymphocytes were performed in top parallel. In the histogram, the red line depicts background fluorescence while the blue line depicts fluorescence in Dill ${ }_{18}$ or calcein AM single-stained lymphocytes and il $_{18^{-}}$ calcein double-stained lymphocytes. Isolated peripheral blood lymphocytes from Wistar-Kyoto (WKY) rats and SHR were stained with calcein AM or Dill ${ }_{18}$, and co-cultured for $3 \mathrm{~h}$ in the absence or presence of Con A (5 $\mathrm{g} / \mathrm{ml})$ and Gap27 $(500 \mu \mathrm{M})$ as described in the Materials and Methods section. Direct calcein AM transfer through GJCs from donor lymphocytes (calcein AM single-stained cells) to recipient lymphocytes ( Dill $C_{18}$ single-stained cells) was assessed using flow cytometry. Dill ${ }_{18}$-calcein AM double-stained fluorescent cells expressed as a percentage of the total number of peripheral blood lymphocytes. The effect of Gap27 on GJIC of the co-cultured peripheral blood lymphocytes was studied. $\mathbf{b}$ - Bar graph of the mean percentages of Dill ${ }_{18}$-calcein double-positive cells from three independent experiments \pm SEM. ${ }^{\& \&} p<0.01$ versus WKY group. ${ }^{*} p<0.05$, compared with the control group in the same column $(n=5) ;{ }^{*} p<0.05$, compared with the Con A-stimulated group in the same column $(n=5)$
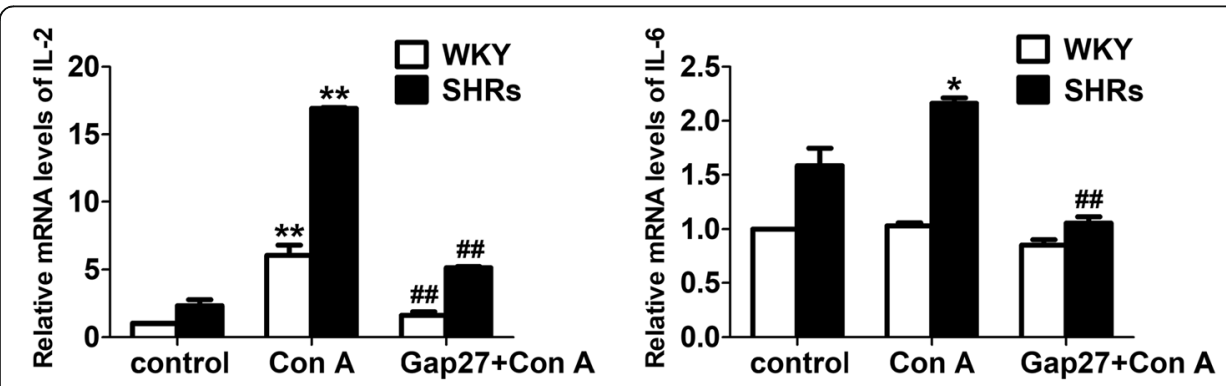

Fig. 6 Gap27 inhibits the mANA expressions of IL-2 and IL-6 from Con A-stimulated PBMCs of spontaneously hypertensive rats (SARs) and Wistar-Kyoto (WKY) rats. A set of PBMCs from SHR and WKY rats were stimulated with Con A $(5 \mu \mathrm{g} / \mathrm{ml})$ for $24 \mathrm{~h}$ in culture medium. After pre-incubation with Gap27 $(500 \mu \mathrm{M})$ for $48 \mathrm{~h}$, a second set of PBMCs were incubated with Con A (5 $\mathrm{g} / \mathrm{ml})$ for another $24 \mathrm{~h}$. Both underwent quantitative real-time PCR analysis. The relative ERNA levels of $I L-2$ and $I L-6$ in PBMCs. $G A P D H$ RNA was used as internal control. Values are the meas \pm SEM from three independent experiments. ${ }^{* *} p<0.01$, compared with the control group in the same column $(n=5) ;{ }^{\# \#} p<0.01$, compared with the Con A-stimulated group in the same column $(n=5)$ 
studies have not investigated the link between the expressional or functional changes in Cxs of $\mathrm{T}$ cell subtypes and abnormal alterations of $\mathrm{T}$ cell subtypes or in the increase in pro-inflammatory cytokine production in hypertension. To better understand the mechanisms of Cxs regulating hypertension-mediated inflammation, we investigated the possible regulatory effect of Cxs on alterations in the percentages of T-lymphocyte subsets, T-lymphocyte proliferation and pro-inflammatory cytokine synthesis in the peripheral blood of hypertensive rats.

Hypertensive stimuli like Ang II, high salt and excessive catecholamines lead to the formation of effector $\mathrm{T}$ cells, resulting in the development of prehypertension [34]. There is evidence to suggest that factors like Ang II promote elevation of blood pressure, increase the expression of pro-inflammatory cytokines, and induce both proliferation of splenic lymphocytes and cytokine production through receptors on immune cells $[3,35]$. Ang II and DOCA-salt also significantly increase vascular and renal infiltration of $\mathrm{CD}^{+}$and $\mathrm{CD}^{+}{ }^{+} \mathrm{T}$ cells in male animals [5]. Initial elevations in blood pressure during prehypertension may in turn lead to T-cell activation [34]. Activated T cells and $\mathrm{T}$ cell-driven cytokines that cause vasoconstriction and vascular remodeling ultimate contribute to the development of hypertension [34]. On the other hand, chronic inflammation is now recognized as a contributing factor to many age-associated diseases, including metabolic disorders, arthritis, neurodegeneration and cardiovascular disease [36]. Indeed, several studies from hypertensive rat and mouse models showed that both $\mathrm{CD} 4^{+}$and $\mathrm{CD}^{+} \mathrm{T}$ cells are involved in the pathogenesis of hypertension, and $\mathrm{CD} 4^{+}$cells are the main adaptive immune players in hypertension [4,5]. 24-week old male SHRs also showed increased helper (CD4) T cell infiltration and a high $\mathrm{CD} 4^{+} / \mathrm{CD} 8^{+}$ratio [37]. In our study, we compared the different lymphocyte subsets, including T-helper cells $\left(\mathrm{CD}^{+} \mathrm{CD}^{+}\right)$, cytotoxic T-cells $\left(\mathrm{CD}^{+}{ }^{+} \mathrm{CD} 8^{+}\right)$, and Treg cells $\left(\mathrm{CD} 4^{+} \mathrm{CD} 25^{+}\right)$, in the peripheral blood of spontaneously hypertensive rats (SHRs) and WKY rats. Our results showed significantly higher tail blood pressure in SHRs compared to WKY rats. We also found an increase in the accumulation of $\mathrm{CD} 4^{+} \mathrm{T}$ cells and in the $\mathrm{CD} 4^{+} / \mathrm{CD} 8^{+}$ratio occurred in the peripheral blood of SHRs. This was evident in the increased secretion of IL-2, IL-4 and IL-6, which are the secretory products of activated T lymphocytes. Taken together with the results of the previous studies described above, these findings suggest that $\mathrm{CD} 4^{+} \mathrm{T}$-cell irregularities contribute to the development of hypertension, with a reciprocal relationship to blood pressure elevation and cytokine production. Furthermore, hypertensive patients, Ang II-infused male Rag- $1^{-/-}$mice and male SHRs exhibit significantly greater numbers of cytotoxic $\mathrm{CD}^{+} \mathrm{CD} 8^{+} \mathrm{T}$ cells $[5,38]$. CD8-deficient mice have a blunted hypertensive response, and adoptive transfer of CD8 into Rag1-deficient mice recovers a normal blood pressure increase during Ang II administration [16]. However, our results and other data from our lab showed that the percentages of $\mathrm{CD} 8^{+} \mathrm{T}$ cells in the peripheral blood of SHRs and essential hypertensive patients [27] were reduced, which may be caused by enhanced infiltration of $\mathrm{CD}^{+} \mathrm{T}$ cells into other tissues. Thus, we can speculate here that the decrease in the number of activated $\mathrm{CD}^{+} \mathrm{T}$ cells represents general immunological dysregulation in hypertensive rats, although the cause is not entirely clear from this study. In contrast to pro-inflammatory $\mathrm{T}$ cells, CD $4{ }^{+} \mathrm{CD} 25^{+}$Treg cells with immunosuppressive capabilities are considered a 
blocking modulator that can ameliorate blood pressure elevation in response to Ang II or aldosterone [12, 14, 16], whereas DOCA-salt and Ang II stimuli caused a reduction in Tregs in animals [12, 39]. Thus, an imbalance between effector $\mathrm{T}$ lymphocytes and Tregs also represents a crucial mechanism in hypertensionmediated inflammation. Data from our laboratory has also shown that spleen of SHRs presented a significantly decreased percentage of $\mathrm{CD} 44^{+} \mathrm{CD} 25^{+}$(Treg) $\mathrm{T}$ cells [40]. We have here provided evidence that $\mathrm{CD} 4^{+} \mathrm{CD} 25^{+} \mathrm{T}$ cells are markedly diminished in the peripheral blood of SHRs, suggesting that lower Tregs prevail in hypertension-mediated inflammation. This demonstrates that imbalance in Treg function or number improves hypertension-mediated inflammation and is an important factor in the development of hypertension.

Several pro-inflammatory cytokines (IL-2, IL-4 and IL-6) secreted by T cells were shown to be elevated in the serum of many hypertensive models and hypertensive patients, contributing to the inflammation of blood vessels $[15,16]$. In this study, compared with WKY rats, SHRs had higher serum levels of IL-2, IL-4 and IL-6. IL-6 is fundamental for the development of stress-induced hypertension [41]. Increased IL-6 levels suppress $\mathrm{CD}^{+}$naïve T-cell differentiation into Tregs [42]. These findings together with our results strongly support the essential roles of IL-2, IL-4 and IL-6 in the development of hypertension.

Although considerable research, including our work, has shown that the disorder of lymphocyte subtypes plays an important role in hypertension, the precise mechanisms underlying this role remain unclear. Comprehending how T-lymphocyte subsets become imbalanced and participate in hypertension-mediated inflammation is crucial. Growing evidence indicates that Cxs-based channels play an indispensable role in modulating the clonal expansion of $\mathrm{CD}^{+} \mathrm{T}$ cells and the production of cytokines [28, 43]. $\mathrm{Cx} 40$ and $\mathrm{Cx} 43$ are the main Cxs in almost all immune cells, with the predominant expression of Cx43 in circulating lymphocytes [22] and Cx43 acts in a pro-inflammatory way $[44,45]$. Recently, it was reported that activation of CD4 ${ }^{+} \mathrm{T}$ cells is associated with an upregulation of Cx43 expression [43]. During T-cell activation, the expression of GJCs and HCs mainly constituted by Cx43 contributes to clonal expansion of T cells [43]. Moreover, expression or accumulation of Cxs (Cx40 and Cx43) in the plasma membranes and/or cytoplasm of $\mathrm{T}$ lymphocytes are actively regulated by pro-inflammatory molecules such as LPS, mitogen, anti-CD3/anti-CD28 beads and numerous cytokines (TNF- $\alpha$ Plus IFN- $\gamma$ ) $[25,29,30]$. However, it is uncertain whether hypertension-mediated inflammation induces upregulation of Cxs expression in T-lymphocyte subsets, and whether Cxs are also implicated in hypertensive inflammation-induced alterations in the production of pro-inflammatory cytokines. Excitingly, our results clearly showed that surface and/or cytoplasmic expression of $\mathrm{Cx} 40$ and Cx43 in peripheral blood lymphocytes and $\mathrm{CD}^{+} / \mathrm{CD}^{+} \mathrm{T}$ cells were significantly increased in SHRs. In addition, we also found a strong correlation between the serum levels of pro-inflammatory cytokines (IL-2 and IL-6) and the expression levels of Cx40 or Cx43 in SHRs. Although T, B and NK cells from secondary lymphoid organs have been shown to express $\mathrm{Cx} 40$ at a low level [30], the contribution of $\mathrm{Cx} 40$ to the activation and proliferation of lymphocytes is still unknown. It has been proposed that Cx40-formed hemi-channels facilitate ATP-mediated propagation of calcium ions, but this is speculative $[32,46]$. Thus, the role of $\mathrm{Cx} 40$ in T-lymphocytes remains to be further 
investigated. Above all, these results provide an explanation for the importance of pro-inflammatory cytokines in the maintenance of Cxs expression, and the association between hypertension-mediated inflammation and the upregulation of Cxs expression in peripheral blood lymphocytes. Most notably, it is believed that Cxs can be upregulated when immune cells become exposed to inflammatory factors [45].

Cx43-based channels have been reported to be directly implicated in intercellular communication between human peripheral blood lymphocytes or PBMCs [30, 31]. The functionality of GJIC through Cx43-based channels is regulated by inflammatory stimulators (LPS and PHA) [20], and Cx43 expression can be induced by cytokines in monocytes and DCs [29, 47], whereas blocking of Cx43-based channels remarkably reduced cytokine secretion (IFN- $\gamma$, IL-2 and IL-10) by T cells and thereby suppressed the inflammatory response $[22,25,31]$. This evidence clearly demonstrates that the regulative relationship between $\mathrm{Cx} 43$-mediated cellular communication and the production of pro-inflammatory cytokines is reciprocal, which may be involved in the pathological mechanisms of hypertensive inflammation. Our previous studies have also demonstrated that pro-inflammatory cytokines (IL-2) or essential hypertension promote cellular communication in peripheral blood lymphocytes and the production of IFN- $\gamma$ and TNF- $\alpha$ [27]. In agreement with our previous observations, our new results also show a promoting effect of hypertension or the T-cell mitogen (Con A) on calcein dye transfer between peripheral blood lymphocytes, and enhanced mRNA expression levels of $I L-2$ and IL-6 in Con A-stimulated lymphocytes from SHRs. An important implication of our data is that the enhanced GJIC in lymphocytes from SHRs may be involved in the hypertensive inflammatory response. In the presence of a specific inhibitor of $\mathrm{Cx} 43$, we observed diminished dye coupling from calcein donor cells to receptor cells in SHRs, and reduced $I L-2$ and $I L-6$ expressions in Con A-stimulated peripheral blood lymphocytes of SHRs. This is similar to our previous findings in the lymphocytes of both essential hypertensive patients and normotensive healthy subjects [27]. These results indicate that inhibition of Cx43-based channels may result in disrupted GJIC between peripheral blood lymphocytes and in a reduction in pro-inflammatory cytokines. This further supports a direct correlation between Cx43-mediated GJIC in lymphocytes and hypertension-mediated inflammation or the production of cytokines. The inhibition was not complete, which may be due to the high connexin membrane turnover under inflammatory stimulus by Con A. Another reason for the lack of complete inhibition of GJIC is that Gap27 may not completely inhibit heterotypic junctions constructed of Cx40/Cx43 [46]

Although Gap27 inhibits Cx43-mediated intercellular communication, it also suppresses Cx37-based GJCs, pannexin channel currents [48] and Cx43-based HCs [49, 50]. However, the expression of Cx37 in the immune system has appeared only in lymphatic vessels, resting monocytes and cell lines derived from macrophages (macrophage foam cells) $[20,51]$. There is also compelling evidence that Cx37 is not found in peripheral blood and tonsil lymphocytes [30, 52]. It is almost impossible for there to be any Cx37-mediated GJIC between peripheral blood lymphocytes. Therefore, Gap27 acts mainly on Cx43-mediated channels or hemi-channels in our study. The inhibitory kinetics of GJCs and HCs by Gap27 are different, with inhibition of HCs occurring more rapidly (minutes) than inhibition of GJCs (tens of minutes to hours) [50]. Based on this observation, the incubation time of Gap27 is long enough to completely block the 
Cx43-based GJC-mediated inflammatory response in our study, but the involvement of Cxs- and Panx1-based HCs cannot be excluded. Thus, our results above using Gap27 incubation are very likely related to a combined effect on the inhibition of Cx43-mediated channels and hemi-channels. In contrast to GJCs, HCs are believed to specifically open up in pathological conditions and affect pro-inflammatory cytokine production and proliferation of T cells through ATP release [20, 23]. However, HCs involvement in hypertension-mediated inflammation remains to be investigated. Further studies using the HC-specific mimetic peptide Gap19 and Peptide5 [18] in combination with lentivirus-mediated RNAi knockdown of Cx43 may discern the contribution of $\mathrm{HCs}$ in immune cells to hypertension-mediated inflammation.

\section{Conclusions}

Our results suggest the importance of Cxs, in particular Cx43, on $\mathrm{T}$ lymphocytes in hypertension-mediated inflammation. Based on results of a comparison of Wistar-Kyoto and spontaneous hypertensive rats, we can speculate that $\mathrm{Cx} 43$ expression and Cx43-mediated gap junctional intracellular communication (GJIC) are involved in the regulation of T-lymphocyte subset balance and production of pro-inflammatory cytokines during hypertension. Targeted interventions in the Cx43-mediated GJ in various immune cells could represent a new therapeutic strategy for the treatment of hypertension.

\section{Abbreviations}

Ang II: Angiotensin II; BW: Body Weight; Con A: Concanavalin A; Cx-HCs: Cxs-based hemichannels; Cxs: Connexins ; ELISA: Enzyme-linked immunosorbent assay; GJCs: Gap junction channels; GJIC: Gap junctional intracellular communication; HCs: Hemi-channels; PBMCs: Peripheral Blood Mononuclear Cells; SBP: Systolic Blood Pressure; SHRs: Spontaneously Hypertensive Rats; SW: Spleen Weight

Funding

This work was supported by grants from the National Natural Science Foundation of China (Nos. 81660271 to Ke-tao Ma, 81460098 to Xin-zhi Li, 81600325 to Liang Zhang and 81560081 to Jun-qiang Si). International Cooperation Project of Shihezi University (Nos. GJHZ201603 to Ke-tao Ma).

Availability of data and materials

All data and materials involved in this report are available to readers.

Authors' contributions

KTM conceived and designed the experiments. XN, XZL and AW performed the experiments. KTM, XZL and LZ analyzed the data. HCZ, LL and JQS contributed reagents, materials and analysis tools. LZ wrote the paper. All authors read and approved the final manuscript.

Authors' information

Xin-zhi Li is from the Department of Pathophysiology of the Medical College of Shihezi University. The other authors are from the Department of Physiology of the Medical College of Shihezi University.

Ethics approval

This manuscript does not report on studies involving human participants, human data or human tissue. The protocol of the study was approved by Institutional Animal Care and Use Committees (IACUC) of the Medical College of Shihezi University, and all animal handling and experimental procedures were performed in accordance with guidelines for the Care and Use of Laboratory Animals published by the US National Institutes of Health (Public Health Service Policy on Humane Care and Use of Animals, DHEW Publication No. 96-01, PHS Policy revised in 2002).

\section{Consent for publication}

Not applicable 


\section{Publisher's Note}

Springer Nature remains neutral with regard to jurisdictional claims in published maps and institutional affiliations.

\section{Author details}

${ }^{1}$ Department of Physiology, Medical College of Shihezi University, 59 North 2nd Road, Shihezi, Xinjiang 832002, People's Republic of China. ${ }^{2}$ Key Laboratory of Xingjiang Endemic and Ethnic Diseases, Medical College of Shihezi University, Shihezi, Xinjiang, China. ${ }^{3}$ Department of Pathophysiology, Medical College of Shihezi University, Shihezi, Xinjiang, China.

Received: 15 January 2018 Accepted: 6 August 2018

Published online: 20 August 2018

\section{References}

1. Chen S, Agrawal DK. Dysregulation of T cell subsets in the pathogenesis of hypertension. Curr Hypertens Rep. 2015;17:8.

2. Marvar PJ, Vinh A, Thabet S, et al. T lymphocytes and vascular inflammation contribute to stress-dependent hypertension. Biol Psychiatry. 2012;71:774-82

3. Harrison DG, Vinh A, Lob H, Madhur MS. Role of the adaptive immune system in hypertension. Curr Opin Pharmacol. 2010;10:203-7.

4. Virdis A, Dell'Agnello U, Taddei S. Impact of inflammation on vascular disease in hypertension. Maturitas. 2014;8:179-83.

5. Tipton AJ, Sullivan JC. Sex differences in T cells in hypertension. Clin Ther. 2014;36:1882-900.

6. Guzik TJ, Hoch NE, Brown KA, et al. Role of the T cell in the genesis of angiotensin II induced hypertension and vascular dysfunction. J Exp Med. 2007;204:2449-60

7. Solak Y, Afsar B, Vaziri ND, et al. Hypertension as an autoimmune and inflammatory disease. Hypertens Res. 2016;39:567-73.

8. Idris-Khodja N, Mian MO, Paradis P, Schiffrin EL. Dual opposing roles of adaptive immunity in hypertension. Eur Heart J. 2014;35:1238-44

9. Tinsley $\mathrm{JH}$, Chiasson VL, South $\mathrm{S}$, et al. Immunosuppression improves blood pressure and endothelial function in a rat model of pregnancy-induced hypertension. Am J Hypertens. 2009;22:1107-14.

10. Harrison DG, Marvar PJ, Titze JM. Vascular inflammatory cells in hypertension. Front Physiol. 2012:3:128.

11. Rodriguez-Iturbe B, Pons H, Johnson RJ. Role of the Immune System in Hypertension. Physiol Rev. 2017; 97(3):1127-64.

12. Barhoumi T, Kasal DA, Li MW, et al. T regulatory lymphocytes prevent angiotensin II-induced hypertension and vascular injury. Hypertension. 2011;57:469-76.

13. Matrougui $K$, Abd Elmageed Z, Kassan M, et al. Natural regulatory T cells control coronary arteriolar endothelial dysfunction in hypertensive mice. Am J Pathol. 2011;178:434-41.

14. Kasal DA, Barhoumi T, Li MW, et al. T regulatory lymphocytes prevent aldosterone-induced vascular injury. Hypertension. 2012:59:324-30

15. Schiffrin EL. Immune mechanisms in hypertension and vascular injury. Clin Sci (Lond). 2014;126:267-74.

16. Zhang J, Crowley SD. Role of T lymphocytes in hypertension. Curr Opin Pharmacol. 2015;21:14-9.

17. Savoia C, Schiffrin EL. Vascular inflammation in hypertension and diabetes: molecular mechanisms and therapeutic interventions. Clin Sci (Lond). 2007;112:375-84

18. Willebrords J, Crespo Yanguas S, Maes M, et al. Connexins and their channels in inflammation. Crit Rev Biochem Mol Biol. 2016;51:413-39.

19. Su V, Lau AF. Connexins: mechanisms regulating protein levels and intercellular communication. FEBS Lett. 2014;588: $1212-20$.

20. Sáez PJ, Shoji KF, Aguirre A, Sáez JC. Regulation of hemichannels and gap junction channels by cytokines in antigenpresenting cells. Mediat Inflamm. 2014;2014:742734.

21. Neijssen J, Pang B, Neefjes J. Gap junction-mediated intercellular communication in the immune system. Prog Biophys Mol Biol. 2007;94:207-18.

22. Bermudez-Fajardo A, Ylihärsilä M, Evans WH, et al. CD4 ${ }^{+}$T lymphocyte subsets express connexin 43 and establish gap junction channel communication with macrophages in vitro. J Leukoc Biol. 2007:82:608-12.

23. Glass AM, Snyder EG, Taffet SM. Connexins and pannexins in the immune system and lymphatic organs. Cell Mol Life Sci. 2015;72:2899-910.

24. Elgueta R, Tobar JA, Shoji KF, et al. Gap junctions at the dendritic cell-T cell interface are key elements for antigendependent T cell activation. J Immunol. 2009;183:277-84.

25. Mendoza-Naranjo A, Bouma G, Pereda C, et al. Functional gap junctions accumulate at the immunological synapse and contribute to T cell activation. J Immunol. 2011;187:3121-32

26. Ni X, Zhang L, Peng $M$, et al. Hydrogen sulfide attenuates hypertensive inflammation via regulating Connexin expression in spontaneously hypertensive rats. Med Sci Monit. 2018;24:1205-18.

27. Ni X, Wang A, Zhang $L$, et al. Up-regulation of gap junction in peripheral blood T lymphocytes contributes to the inflammatory response in essential hypertension. PLoS One. 2017;12(9):e0184773.

28. Shao J, Nangaku M, Miyata T, et al. Imbalance of T-cell subsets in angiotensin II-infused hypertensive rats with kidney injury. Hypertension. 2003:42:31-8.

29. Eugenín EA, Brañes MC, Berman JW, Sáez JC. TNF-alpha plus IFN-gamma induce connexin43 expression and formation of gap junctions between human monocytes/macrophages that enhance physiological responses. J Immunol. 2003;170:1320-8.

30. Oviedo-Orta E, Hoy T, Evans WH. Intercellular communication in the immune system: differential expression of connexin40 and 43 , and perturbation of gap junction channel functions in peripheral blood and tonsil human lymphocyte subpopulations. Immunology. 2000;99:578-90.

31. Tittarelli A, Mendoza-Naranjo A, Farías M, et al. Gap junction intercellular communications regulate NK cell activation and modulate NK cytotoxic capacity. J Immunol. 2014;192:1313-9.

32. Oviedo-Orta E, Gasque P, Evans WH. Immunoglobulin and cytokine expression in mixed lymphocyte cultures is reduced by disruption of gap junction intercellular communication. FASEB J. 2001;15:768-74. 
33. McMaster WG, Kirabo A, Madhur MS, Harrison DG. Inflammation, immunity, and hypertensive end-organ damage. Circ Res. 2015;116:1022-33.

34. Harrison DG, Guzik TJ, Lob HE, et al. Inflammation, immunity, and hypertension. Hypertension. 2011;57:132-40.

35. Ganta CK, Lu N, Helwig BG, et al. Central angiotensin II-enhanced splenic cytokine gene expression is mediated by the sympathetic nervous system. Am J Physiol Heart Circ Physiol. 2005;289(4):H1683-91.

36. Alexander M, O'Connell RM. Noncoding RNAs and chronic inflammation: micro-managing the fire within. BioEssays. 2015;37(9):1005-15

37. Rodriguez-Iturbe B, Quiroz Y, Ferrebuz A, et al. Evolution of renal interstitial inflammation and NF-kappab activation in spontaneously hypertensive rats. Am J Nephrol. 2004;24:587-94.

38. Pollow DP, Uhrlaub J, Romero-Aleshire M, et al. Sex differences in T-lymphocyte tissue infiltration and development of angiotensin II hypertension. Hypertension. 2014;64:384-90.

39. Amador CA, Barrientos V, Peña J, et al. Spironolactone decreases DOCA-salt-induced organ damage by blocking the activation of T helper 17 and the downregulation of regulatory T lymphocytes. Hypertension. 2014;63:797-803.

40. Zhang $H C$, Zhang ZS, Zhang $L$, et al. Connexin 43 in splenic lymphocytes is involved in the regulation of $C D 4^{+} C D 25^{+} T$ Iymphocyte proliferation and cytokine production in hypertensive inflammation. Int J Mol Med. 2018;41(1):13-24.

41. De Miguel C, Rudemiller NP, Abais JM, Mattson DL. Inflammation and hypertension: new understandings and potential therapeutic targets. Curr Hypertens Rep. 2015:17:507.

42. Kimura A, Kishimoto T. IL-6: regulator of Treg/Th17 balance. Eur J Immunol. 2010;40:1830-5.

43. Oviedo-Orta E, Perreau M, Evans WH, Potolicchio I. Control of the proliferation of activated CD4 ${ }^{+} \mathrm{T}$ cells by connexins. J Leukoc Biol. 2010;88:79-86.

44. Abed A, Dussaule JC, Boffa JJ, et al. Connexins in renal endothelial function and dysfunction. Cardiovasc Hematol Disord Drug Targets. 2014;14:15-21.

45. Abed A, Toubas J, Kavvadas P, et al. Targeting connexin 43 protects against the progression of experimental chronic kidney disease in mice. Kidney Int. 2014;86:768-79.

46. Oviedo-Orta E, Errington RJ, Evans WH. Gap junction intercellular communication during lymphocyte transendothelial migration. Cell Biol Int. 2002;26(3):253-63.

47. Corvalán LA, Araya R, Brañes MC, et al. Injury of skeletal muscle and specific cytokines induce the expression of gap junction channels in mouse dendritic cells. J Cell Physiol. 2007:211:649-60.

48. Wang J, Ma M, Locovei S, et al. Modulation of membrane channel currents by gap junction protein mimetic peptides: size matters. Am J Physiol Cell Physiol. 2007;293:C1112-9.

49. Li X, Zhao H, Tan $\mathrm{X}$, et al. Inhibition of connexin43 improves functional recovery after ischemic brain injury in neonatal rats. Glia. 2015;63(9):1553-67.

50. Sáez JC, Leybaert L. Hunting for connexin hemichannels. FEBS Lett. 2014;588:1205-11.

51. Chanson M, Derouette JP, Roth I, et al. Gap junctional communication in tissue inflammation and repair. Biochim Biophys Acta. 2005;1711(2):197-207.

52. Alves LA, de Carvalho AC, Savino W. Gap junctions: a novel route for direct cell-cell communication in the immune system? Immunol Today. 1998;19(6):269-75.

Ready to submit your research? Choose BMC and benefit from:

- fast, convenient online submission

- thorough peer review by experienced researchers in your field

- rapid publication on acceptance

- support for research data, including large and complex data types

- gold Open Access which fosters wider collaboration and increased citations

- maximum visibility for your research: over 100M website views per year

At $\mathrm{BMC}$, research is always in progress.

Learn more biomedcentral.com/submissions 